\title{
Complexes of Glycolic Acid with Nitrogen Isolated in Argon Matrices. I. Structures and Thermal Effects
}

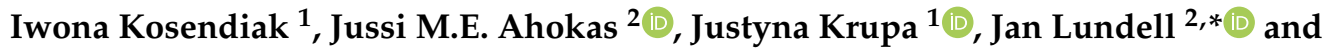 \\ Maria Wierzejewska ${ }^{1, *}$ \\ 1 Faculty of Chemistry, University of Wroclaw, Joliot-Curie 14, 50-383 Wroclaw, Poland \\ 2 Department of Chemistry, University of Jyvaskyla, P.O.Box 35, 40014 Jyvaskyla, Finland \\ * Correspondence: jan.c.lundell@jyu.fi (J.L.); maria.wierzejewska@chem.uni.wroc.pl (M.W.); \\ Tel.: +358-40-744-5270 (J.L.); +48-71-375-7332 (M.W.)
}

Received: 29 July 2019; Accepted: 5 September 2019; Published: 7 September 2019 updates

\begin{abstract}
Molecular complexes between glycolic acid and nitrogen were studied in a low-temperature argon matrix with FTIR spectroscopy, and supported by MP2 and BLYPD3 calculations. The calculations indicate 11 and 10 stable complex structures at the MP2 and BLYPD3 levels of theories, respectively. However, only one hydrogen-bonded complex structure involving the most stable SSC conformer of glycolic acid was found experimentally, where the nitrogen molecule is bound with the carboxylic $\mathrm{OH}$ group of the SSC conformer. The complex shows a rich site structure variation upon deposition of the matrix in different temperatures and upon annealing experiments, which provide interesting prospects for site-selective chemistry.
\end{abstract}

Keywords: hydrogen bond; matrix isolation; carboxylic acid; computational chemistry; vibrational spectroscopy

\section{Introduction}

Hydrogen bonding is a significant non-covalent interaction that plays an important role in many areas of biology and chemistry [1,2]. Weakly bound molecular complexes with hydrogen bond or van der Waals interactions are frequently encountered in atmospheric chemistry and are known to affect both chemical and photochemical processes [3-5]. In complexes, the electronic, vibrational and rotational levels are disturbed as a result of interaction between complex subunits, and this leads to changes in spectral and photochemical characteristics of the complex components. On the other hand, weakly bound complexes frequently represent shallow energy minima on their potential energy surfaces, which lead to thermodynamic instability of such species at room temperature. From this point of view, the low temperature matrix isolation technique coupled with different spectroscopic methods is a very useful technique to trap and to study weakly bound complexes [6,7]. Recently, it was demonstrated that matrix isolation technique connected with computational studies is a powerful approach to study hydrogen bonds and other intermolecular interactions in complexes involving atmospheric constituents or species related to tropospheric IR-induced chemistry [8-14].

Glycolic acid (GA), the simplest $\alpha$-hydroxycarboxylic acid with two $\mathrm{OH}$ groups, is capable of forming both intra- and intermolecular hydrogen bonds. As such, GA is a model species to study in order to understand how competing $\mathrm{OH}$-groups in the molecule affect the chemical reactivity and capability to form molecular complexes. Several reports on monomeric GA isolated in low-temperature matrices as well as its transformations have appeared in the literature [15-20]. The structures of the three most stable GA species are presented in Figure 1. Among the monomer structures, the most stable conformer is the SSC form, which is stabilized by the $\mathrm{O}-\mathrm{H} \cdots \mathrm{O}$ intramolecular hydrogen bond. This conformer is present in the gas phase and in low-temperature matrices with an estimated population 
at room temperature of ca. 95\%. A small amount of two less stable GAC and AAT conformers has also been detected $[19,20]$.
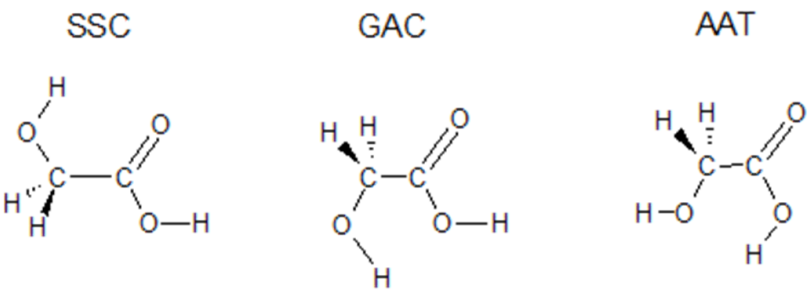

Figure 1. Structures of the three most stable conformers of glycolic acid monomer.

Contrary to the monomeric GA, only two studies on GA complexes in low-temperature matrices have appeared in literature. Recently, a study on GA dimers revealed for the first time information on three cyclic GA dimers identified in an argon matrix [21]. All of these dimers were formed between SSC conformers: one dimer with hydrogen bonds between the two carboxylic $\mathrm{OH}$ groups, one structure with hydrogen bonds between the two alcoholic $\mathrm{OH}$ groups and a mixed structure with one $\mathrm{OH}$ group from the carboxylic group acting as proton donor and the alcoholic $\mathrm{OH}$ group on the other subunit acting as proton acceptor. Molecular complexes between GA and molecular nitrogen were identified in a study applying Raman spectroscopy for argon-trapped species upon high vibrational excitation experiments [22]. In that study, nitrogen was found to form complexes with two GA conformers (SSC and AAT) in low temperature argon environment. However, this study did not scrutinise the actual molecular complex structures involved but only made conclusions of different GA $\cdots \mathrm{N}_{2}$ systems involved based on their behaviour upon $532 \mathrm{~nm}$ irradiation.

These Raman spectroscopy combined with visible light irradiation experiments acted as a prelude to our study presented here. In this paper, we present results of a combined study employing both theoretical methods and FTIR matrix isolation studies on complexes formed between glycolic acid and nitrogen molecule. The target is to study and to identify the 1:1 complexes GA forms with molecular nitrogen. This research is important in order to understand which type of complexes can be formed, if such species are experimentally detected, and, as these formed complexes are used as precursors for near-infrared irradiation experiments, if their photo-induced chemistry differ from isolated GA monomers. The study on the NIR irradiated GA-N 2 complexes is reported separately in a following paper taking advantage of the results presented here.

\section{Experimental and Computational Details}

The matrix samples were prepared by passing mixtures of high purity argon (Messer, 5.0) and nitrogen (Messer, 6.0) with the $\mathrm{N}_{2}$ /Ar ratios of $1 / 4000$ through the glass U-tube with glycolic acid (GA) situated outside the cryostat chamber. Optimizing the deposition temperature and matrix flow rate it was possible to obtain matrices containing nearly exclusively monomeric GA and GA $\cdots \mathrm{N}_{2}$ complexes of 1:1 stoichiometry. The GA/ $\mathrm{N}_{2} /$ Ar gaseous mixtures were deposited onto a cold CsI window kept at $15 \mathrm{~K}$ or $18 \mathrm{~K}$ in an APD-Cryogenics (ARS-2HW) closed cycle cryostat. Annealing experiments were performed upon the deposited samples at $33 \mathrm{~K}$. The sample temperature was maintained by a Scientific Instruments 9700 temperature controller equipped with a silicon diode and a resistive heater. FTIR spectra were collected at $10 \mathrm{~K}$ in a transmission mode with a $0.5 \mathrm{~cm}^{-1}$ resolution using a Bruker IFS 66 Fourier Transform spectrometer equipped with a liquid $\mathrm{N}_{2}$ cooled MCT detector.

In order to support the experimental work, computational studies were carried out using the Gaussian16 program package [23]. The calculations were performed for GA: $\mathrm{N}_{2}$ 1:1 complexes for the three most stable conformers (SSC, GAC, AAT) at the MP2 [24-27] and B3LYPD3 [28-32] levels of theory using the $6-311++\mathrm{G}(2 \mathrm{~d}, 2 \mathrm{p})$ basis set. All geometry optimizations were performed with the Boys-Bernardi full counterpoise method by Dannenberg [33,34]. The topological analysis of the electron density (Atoms-In-Molecules, AIM [35]) was performed at the MP2/6-311++G(2d,2p) level 
using AIM studio program (Version 12.09.23, Standard) [36]. The harmonic vibrational wavenumbers and infrared intensities were calculated both at MP2 and B3LYPD3 levels for the optimised structures to assist the analysis of the experimental spectra. The computed spectra were used to verify that computed complex structures were stable structures. Interpretation of the infrared spectra is based mainly on the MP2 results and this data is presented in the text.

\section{Results and Discussion}

\subsection{Structure and Energetics of 1:1 GA $\cdots N_{2}$ Complexes}

Out of seven theoretically predicted conformers of glycolic acid monomer (GA) the three most stable forms, SCC, GAC and AAT, were detected in low-temperature noble gas matrices [19,20]. The fourth SST conformer was identified only in nitrogen matrices upon near-IR excitation of the most stable SSC conformer [19]. Therefore, exclusive interaction of the SSC, GAC and AAT conformers with nitrogen are considered here since these conformers of monomeric GA are the most plausible to appear in a solid argon environment.

At the MP2/6-311++G(2d,2p) level of theory 11 energy minima structures were found for 1:1 GA- $\mathrm{N}_{2}$ complexes whereas the calculations performed at the B3LYPD3 level showed the presence of only ten energy minima structures. All optimized GA $\cdots \mathrm{N}_{2}$ complex structures are shown in Figure 2. The coordinates of all optimised complexes are presented in Table S1 (Supplementary Materials Information).

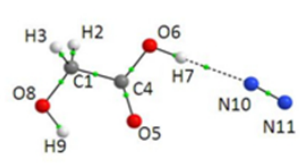

SSC1

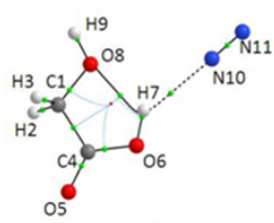

AAT1

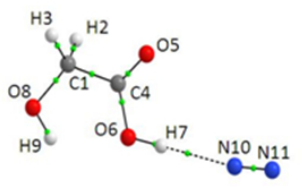

GAC1

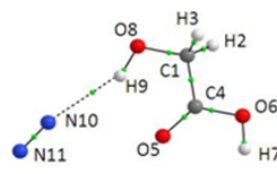

SSC2

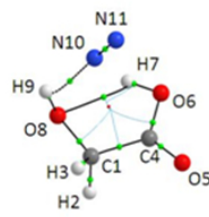

AAT2

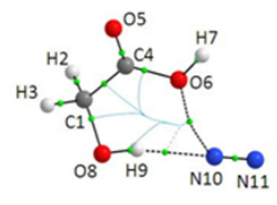

GAC2

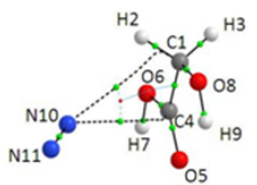

SSC3

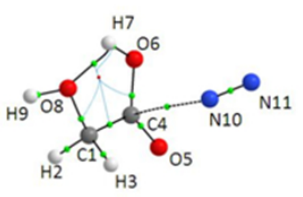

AAT3

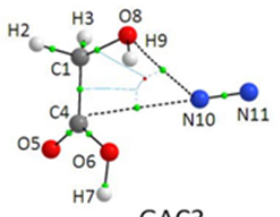

GAC3

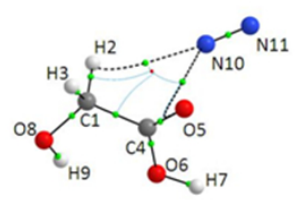

GAC4

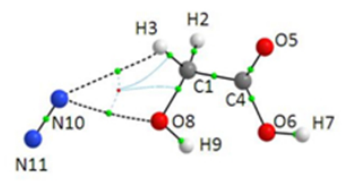

GAC5

Figure 2. The MP2-optimized 1:1 structures of SSC, AAT and GAC complexes with molecular nitrogen.

The AIM approach based on the topological analysis of electron density becomes nowadays almost routine method providing the characteristics of various types of interactions, among them hydrogen bonds and van der Waals interactions [37-39]. Two AIM parameters: the electron density 
$\rho(\mathrm{r})$ and its Laplacian $\nabla^{2} \rho(\mathrm{r})$ at bond critical points (BCP) obtained for all optimized 1:1 structures at $\mathrm{MP} 2 / 6-311++\mathrm{G}(2 \mathrm{~d}, 2 \mathrm{p})$, using the MP2 computed density matrix, are collected in Table 1. Additionally, the positions of the bond $(3,-1)$ critical points derived from the AIM calculations are visualised together with the optimised complex structures in Figure 2.

Table 1. Interatomic distances $(\AA)$, angles (degree) and electron density parameters of the bond (au) of the SSC, GAC and AAT complexes with $\mathrm{N}_{2}(1: 1)$ computed at the MP2/6-311++G(2d,2p) level.

\begin{tabular}{|c|c|c|c|c|c|c|}
\hline \multirow{3}{*}{ Complex } & \multicolumn{3}{|c|}{ Intermolecular Parameters } & \multicolumn{3}{|c|}{ AIM Parameters } \\
\hline & \multicolumn{2}{|c|}{ Interatomic Distances } & \multirow{2}{*}{$\begin{array}{c}\text { Angle } \\
X-H \cdots Y\end{array}$} & \multirow[t]{2}{*}{ BCP } & \multirow[t]{2}{*}{$\rho(\mathrm{r})$} & \multirow[t]{2}{*}{$\nabla^{2} \rho(\mathrm{r})$} \\
\hline & $\mathrm{H} \cdots \mathrm{Y}$ & $X \cdots Y$ & & & & \\
\hline SSC1 & 2.257 & 3.226 & 179.0 & $\mathrm{H} 7 \cdots \mathrm{N} 10$ & 0.014 & 0.053 \\
\hline SSC2 & 2.475 & 3.363 & 152.8 & $\mathrm{H} 9 \cdots \mathrm{N} 10$ & 0.009 & 0.037 \\
\hline \multirow[t]{3}{*}{ SSC3 } & & 3.358 & & $\mathrm{C} 1 \cdots \mathrm{N} 10$ & 0.006 & 0.024 \\
\hline & & 3.280 & & $\mathrm{C} 4 \cdots \mathrm{N} 10$ & 0.006 & 0.024 \\
\hline & \multicolumn{3}{|c|}{ Ring critical point } & & 0.006 & 0.025 \\
\hline GAC1 & 2.262 & 3.230 & 178.1 & $\mathrm{H} 7 \cdots \mathrm{N} 10$ & 0.014 & 0.053 \\
\hline \multirow[t]{3}{*}{ GAC2 } & 2.363 & 3.304 & 166.4 & $\mathrm{H} 9 \cdots \mathrm{N} 10$ & 0.012 & 0.045 \\
\hline & & 3.410 & & O6 $\cdots$ N10 & 0.004 & 0.016 \\
\hline & \multicolumn{3}{|c|}{ Ring critical point } & & 0.004 & 0.016 \\
\hline \multirow[t]{3}{*}{ GAC3 } & \multicolumn{3}{|c|}{3.249} & O8 $\cdots$ N10 & 0.006 & 0.022 \\
\hline & \multirow{2}{*}{\multicolumn{3}{|c|}{$\begin{array}{l}\quad 3.252 \\
\text { Ring critical point }\end{array}$}} & $\mathrm{C} 4 \cdots \mathrm{N} 10$ & 0.006 & 0.026 \\
\hline & & & & & 0.005 & 0.025 \\
\hline \multirow[t]{3}{*}{ GAC4 } & \multirow{3}{*}{2.971} & 3.323 & & O5 $\cdots$ N10 & 0.006 & 0.023 \\
\hline & & 3.684 & 123.1 & $\mathrm{H} 2 \cdots \mathrm{N} 10$ & 0.005 & 0.017 \\
\hline & & ritical po & & & 0.005 & 0.018 \\
\hline \multirow[t]{3}{*}{ GAC5 } & \multirow[t]{3}{*}{2.832} & 3.521 & 121.5 & H3 $\cdots$ N10 & 0.004 & 0.016 \\
\hline & & 3.188 & & O $8 \cdots \mathrm{N} 10$ & 0.005 & 0.018 \\
\hline & & ritical po & & & 0.004 & 0.018 \\
\hline \multirow[t]{3}{*}{ AAT1 } & 2.459 & 3.212 & 134.2 & H7 $\cdots$ N10 & 0.010 & 0.040 \\
\hline & 1.950 & 2.584 & 120.7 & $\mathrm{H} 7 \cdots \mathrm{O} 8$ & 0.027 & 0.117 \\
\hline & & ritical po & & & 0.025 & 0.143 \\
\hline \multirow[t]{3}{*}{ AAT2 } & 2.547 & 3.287 & 133.9 & $\mathrm{H} 9 \cdots \mathrm{N} 10$ & 0.008 & 0.030 \\
\hline & 1.985 & 2.640 & 122.7 & H7 $\cdots$ O 8 & 0.028 & 0.108 \\
\hline & & ritical po & & & 0.026 & 0.137 \\
\hline \multirow[t]{3}{*}{ AAT3 } & \multirow[t]{3}{*}{1.922} & 2.575 & 122.2 & 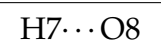 & 0.029 & 0.122 \\
\hline & & 3.184 & & $\mathrm{C} 4 \cdots \mathrm{N} 10$ & 0.006 & 0.027 \\
\hline & & ritical po & & & 0.026 & 0.151 \\
\hline
\end{tabular}

For interaction of SSC with nitrogen three minima were found and two of them contain the $\mathrm{O}-\mathrm{H} \cdots \mathrm{N}$ hydrogen bond formed between carboxylic or alcoholic $\mathrm{OH}$ group and $\mathrm{N}_{2}$ molecule (species denoted SSC1 and SSC2, respectively). In both of these configurations, the $\mathrm{N}_{2}$ molecule lies in the SSC plane. The intermolecular H $\cdots \mathrm{N}$ distance equals 2.257 and $2.475 \AA$ in SSC1 and SSC2, respectively. Interaction with the carboxylic $\mathrm{OH}$ group results in an almost linear hydrogen bond with the $\Theta(\mathrm{O} 6 \mathrm{H} 7 \mathrm{~N} 10)$ angle of $179.0^{\circ}$ whereas in SSC2 the $\mathrm{O}-\mathrm{H} \cdots \mathrm{N}$ bridge is more bent to $\Theta(\mathrm{O} 8 \mathrm{H} 9 \mathrm{~N} 10)=$ $152.8^{\circ}$. In the third SSC- $\mathrm{N}_{2}$ complex (SSC3) the $\mathrm{N}_{2}$ molecule is located above the SSC molecular plane with the N10 atom directed to the centre of the C-C bond. The SSC3 complex also exhibit relatively short N10 . C C1 and N10 . . C4 atomic distances of 3.358 and $3.280 \AA$, respectively. Based on the AIM analysis two van der Waals interaction paths are found between N10 nitrogen atom and C1 or C4 carbon atoms.

Two hydrogen bonded complexes, analogous to those optimized for SSC $\cdots \mathrm{N}_{2}$ were found for both GAC $\cdots \mathrm{N}_{2}$ and AAT $\cdots \mathrm{N}_{2}$ interactions. The intermolecular $\mathrm{H} \cdots \mathrm{N}$ distances are in the range 
of 2.262-2.547 $\AA$. Both GAC1 and GAC2 contain almost linear O-H $\cdots \mathrm{N}$ bridges (178 and $166^{\circ}$, respectively) whereas in AAT1 and AAT2 the hydrogen bond bridges are not linear (in both cases the $\mathrm{O}-\mathrm{H} \cdots \mathrm{N}$ angle equals $134^{\circ}$ ). Similarly to the SSC conformer one non-hydrogen bonded structure (AAT3) was found for AAT. It is characterised by one van der Waals contact between N10 and C1 atoms.

For GAC $\cdots \mathrm{N}_{2}$ complexes three non-hydrogen bonded minima were found (GAC3, GAC4 and GAC5) but none of them corresponds strictly to the structural configurations found for SSC3 or AAT3. Two of these species are characterised by the $\mathrm{C}-\mathrm{H} \cdots \mathrm{N}$ contact and the N10 $\cdots \mathrm{O} 5$ (GAC4) or N10 $\cdots \mathrm{O} 8$ (GAC5) interaction. In the third structure (GAC3) two van der Waals contacts are present between $\mathrm{N} 10 \cdots \mathrm{O} 8$ and N10 $\cdots \mathrm{C} 4$. We do recognise here that the AIM method does not always result to bond paths with chemical meaning $[40,41]$. However, here we use the method to give a brief indication how the complex is built up, and how the nitrogen is connected with the GA subunit, even though some of the AIM bond path charts are very complex and can induce multiple interpretation of the nature of the interaction.

The calculated interaction and relative energies of these species optimised at the MP2 and B3LYPD3 levels are summarised in Table 2.

Table 2. Computed interaction energies and relative energies compared to global minimum SSC1 (in $\mathrm{kJ} \mathrm{mol}^{-1}$ ).

\begin{tabular}{ccccc}
\hline \multirow{2}{*}{ Structure } & \multicolumn{2}{c}{ Interaction Energy } & \multicolumn{2}{c}{ Relative Energy } \\
\cline { 2 - 5 } & MP2 & B3LYPD3 & MP2 & B3LYPD3 \\
\hline SSC1 & -7.70 & -8.41 & 0.00 & 0.00 \\
SSC2 & -4.48 & -5.15 & 3.23 & 3.27 \\
SSC3 & -5.40 & -5.77 & 2.35 & 2.63 \\
GAC1 & -7.53 & -8.28 & 10.70 & 10.49 \\
GAC2 & -5.61 & -6.23 & 12.80 & 12.68 \\
GAC3 & -5.02 & -5.31 & 13.28 & 13.46 \\
GAC4 & -4.48 & -4.94 & 13.75 & 13.78 \\
GAC5 & -4.02 & - & 14.21 & - \\
AAT1 & -4.85 & -5.56 & 15.71 & 16.23 \\
AAT2 & -9.12 & -9.71 & 12.19 & 12.34 \\
AAT3 & -5.40 & -5.73 & 15.08 & 15.91 \\
\hline
\end{tabular}

The most stable structure overall in energy is the SSC1 complex. The other two SSC complexes are about $3 \mathrm{~kJ} \mathrm{~mol}^{-1}$ higher in energy. The GAC and AAT complexes with nitrogen molecule are about 10-14 and 12-15 $\mathrm{kJ} \mathrm{mol}^{-1}$ higher in energy than the complexes of the most stable SSC conformer. These energy differences correspond to the energy differences found for the isolated GA conformers without zero-point nor entropy corrections.

The largest interaction energy among all considered GA $\cdots \mathrm{N}_{2}$ structures is found for the AAT2 complex, which equals to $-9.12 \mathrm{~kJ} \mathrm{~mol}^{-1}$. The interaction in AAT2 is characterised by the alcoholic $\mathrm{O}-\mathrm{H}$ group acting as a proton donor to nitrogen molecule. As can be seen in Table 2 the interaction energies of all other GA complexes are in the range between -4.02 to $-9.12 \mathrm{~kJ} \mathrm{~mol}^{-1}$. Interestingly, both GAC2 and AAT2 complexes with alcoholic $\mathrm{OH}$ group interacting with $\mathrm{N}_{2}$ are characterised by larger interaction energy than that found for the SSC2 form. The GAC and AAT conformers of the GA monomer were found to be about 9.5 and $12.0 \mathrm{~kJ} \mathrm{~mol}^{-1}$ less stable than SSC whereas, for interaction of $\mathrm{N}_{2}$ with the $\mathrm{OH}$ alcoholic group, the situation is reversed. Such an observation was described for glyoxylic acid-water complexes [10] as well.

Looking at the AIM results performed for GAC2 the above situation can be related to the presence of a second weak van der Waals interaction between nitrogen molecule and oxygen atom of the carboxylic $\mathrm{OH}$ group. In turn, according to the AIM calculations, the intramolecular hydrogen bond, existing already in monomeric AAT, formed between the carboxylic $\mathrm{OH}$ and oxygen of the alcoholic $\mathrm{OH}$ becomes stronger in AAT2 complex contributing to its overall stability. In general, the formation of 
an additional van der Waals contact with either of the two $\mathrm{OH}$ groups of the GA subunit strengthens the intermolecular interaction. When no such additional interaction appears, a typical hydrogen-bonded structure as found in SSC1 and GAC1 complexes is prevalent in analogy with previous carboxylic acid complexes with nitrogen molecules [42,43].

\subsection{Computed Spectra}

Infrared and Raman spectra were calculated for all the computationally identified complex structures (see Figure 2). The infrared spectra were used to verify that the optimised structures were stable minima on the potential energy surfaces. Additionally, comparison of complex and monomer spectra is useful for understanding the experimental findings. Raman spectra were also computed, and Raman intensities ( $\mathrm{I}_{\text {Raman }}$ ) were derived from calculated scattering activities values according to the procedure described by Michalska and co-workers [44,45] employing T $=14 \mathrm{~K}$ for the Boltzmann distribution factor and excitation frequency of $532 \mathrm{~nm}\left(18797 \mathrm{~cm}^{-1}\right)$. These values correspond to the experimental conditions used in our previous work on GA $\cdots \mathrm{N}_{2}$ [22]. The computational results obtained at the MP2-level of theory are shown in Table 3 for the most stable SSC1 complex. For comparison, the observed Raman bands have been included in Table 3.

Table 3. Computed band positions for the most stable SSC ${ }^{\cdots} \mathrm{N}_{2}$ complex (SSC1) compared to the experimental Raman band positions $\left(\mathrm{cm}^{-1}\right)$ together with computed infrared $\left(\mathrm{km} \mathrm{mol}^{-1}\right)$ and Raman intensities.

\begin{tabular}{|c|c|c|c|c|}
\hline Mode & Band Position & $\mathbf{I}_{\text {IR }}$ & I Raman $_{\text {R }}$ & Raman Exp [22] \\
\hline$v_{1}$ & 3781 & 79 & 477 & \\
\hline$v_{2}$ & 3754 & 302 & 1880 & $3562,3554,3545$ \\
\hline$v_{3}$ & 3130 & 7 & 1202 & \\
\hline$v_{4}$ & 3087 & 25 & 2536 & \\
\hline$v_{5}$ & 2175 & 1 & 674 & \\
\hline$v_{6}$ & 1789 & 246 & 739 & 1777,1775 \\
\hline$v_{7}$ & 1518 & 12 & 509 & \\
\hline$v_{8}$ & 1492 & 2 & 106 & \\
\hline$v_{9}$ & 1372 & 124 & 202 & \\
\hline$v_{10}$ & 1315 & 33 & 134 & \\
\hline$v_{11}$ & 1271 & 0 & 355 & \\
\hline$v_{12}$ & 1190 & 161 & 175 & \\
\hline$v_{13}$ & 1112 & 226 & 168 & \\
\hline$v_{14}$ & 1053 & 1 & 13 & \\
\hline$v_{15}$ & 878 & 28 & 1107 & \\
\hline$v_{16}$ & 689 & 108 & 16 & \\
\hline$v_{17}$ & 653 & 18 & 518 & \\
\hline$v_{18}$ & 540 & 1 & 204 & \\
\hline$v_{19}$ & 480 & 18 & 528 & \\
\hline$v_{20}$ & 340 & 77 & 7 & \\
\hline$v_{21}$ & 287 & 12 & 32 & \\
\hline$v_{22}$ & 102 & 0 & 1504 & \\
\hline$v_{23}$ & 92 & 8 & 1787 & \\
\hline$v_{24}$ & 80 & 5 & 757 & \\
\hline$v_{25}$ & 79 & 2 & 224 & \\
\hline$v_{26}$ & 23 & 0 & 387 & \\
\hline$v_{27}$ & 18 & 1 & 2940 & \\
\hline
\end{tabular}

The two $\mathrm{OH}$ vibrational bands for $\mathrm{SSC} 1$ are the alcoholic and carboxylic $\mathrm{OH}$ stretching vibrations at 3781 and $3754 \mathrm{~cm}^{-1}$, respectively. Another significant vibrational mode is the carbonyl stretching mode $\left(v_{6}\right)$ that was computed to be at $1789 \mathrm{~cm}^{-1}$. Both of these spectral regions have been probed in the Raman experiments, and GA $\cdots \mathrm{N}_{2}$ complexes have been identified. In order to make assignment of the complex structures appearing in the experiments, infrared and computational data is needed. Here, we 
consider all three SSC complexes found computationally in connection with annealing experiments in solid argon. These results are discussed below that shed light on the complex structures also observed in the Raman experiments [22].

\subsection{Experimental Results}

At first, blank experiments were performed for GA isolated in solid argon. The deposition of GA at $15 \mathrm{~K}$ yielded matrices containing almost exclusively monomers of the acid. The strong bands of the $\mathrm{O}-\mathrm{H}$ and the $\mathrm{C}=\mathrm{O}$ stretching vibrations of the SSC conformer were observed at 3561 and $1773 \mathrm{~cm}^{-1}$. Much weaker absorptions of the two less abundant AAT and GAC conformers were barely observed at 3671,3473 and $1806 \mathrm{~cm}^{-1}$ and 3648,3561 and $1784 \mathrm{~cm}^{-1}$ for AAT and GAC, respectively, in accordance with the predicted gas phase abundances. When the deposition temperature was higher than $15 \mathrm{~K}$ or when the matrix with GA monomers was annealed a number of new weak bands appeared due to the GA dimers [21].

Complex formation between glycolic acid and nitrogen was observed when GA was deposited together with the $\mathrm{N}_{2}$ doped argon with the $\mathrm{N}_{2}$ :Ar ratio of 1:4000 or higher. $\mathrm{New}$ bands due to the $\mathrm{N}_{2}$ complexes with GA appeared in several spectral regions in the vicinity of the GA monomer absorptions. Table 4 contains the most characteristic wavenumber shifts $\left(\Delta v=v_{\text {complex }}-v_{\text {monomer }}\right)$ calculated for the 1:1 species of interest compared to the experimental values. From now on the notation $\mathrm{OH}_{C}$ and $\mathrm{OH}_{\mathrm{A}}$ denotes carboxylic and alcoholic $\mathrm{OH}$ group, respectively.

Table 4. MP2/6-311++G(2d,2p) calculated wavenumber shifts $\Delta v\left(\mathrm{~cm}^{-1}\right)$ and intensities $\left(\mathrm{km} \mathrm{mol}^{-1}\right)$ of the SSC complexes ${ }^{\text {a }}$ with nitrogen compared to the corresponding experimental shifts.

\begin{tabular}{|c|c|c|c|c|c|c|c|}
\hline \multicolumn{6}{|c|}{ MP2/6-311++G(2d,2p) } & \multirow{3}{*}{$\begin{array}{c}\text { Experimental Shifts } \\
\qquad \Delta v\end{array}$} & \multirow{3}{*}{ Assignment } \\
\hline \multicolumn{2}{|c|}{ SSC1 } & \multicolumn{2}{|c|}{ SSC2 } & \multicolumn{2}{|c|}{$\operatorname{SSC} 3 *$} & & \\
\hline$\Delta v$ & I & $\Delta v$ & I & $\Delta v$ & I & & \\
\hline-5 & 79 & 3 & 119 & 0 & 32 & -4 & $\left(v_{1}\right) v \mathrm{OH}_{\mathrm{A}}$ \\
\hline-31 & 302 & 1 & 117 & 0 & 140 & $-11.5,-14.5,-19.0 /-21.0$ & $\left(v_{2}\right) v \mathrm{OH}_{\mathrm{C}}$ \\
\hline-5 & 246 & 1 & 274 & -1 & 249 & $2,-3$ & $\left(v_{6}\right) v \mathrm{C}=\mathrm{O}$ \\
\hline 10 & 124 & -4 & 126 & 1 & 123 & 12,6 & $\left(v_{9}\right) \delta \mathrm{OH}_{\mathrm{A}}+\delta \mathrm{OH}_{\mathrm{C}}+v \mathrm{C}-\mathrm{O}_{\mathrm{C}}$ \\
\hline 15 & 161 & -2 & 126 & 0 & 139 & $14,13,8,5,3$ & $\left(v_{12}\right) \delta \mathrm{OH}_{\mathrm{C}}+v \mathrm{C}-\mathrm{O}_{\mathrm{C}}+\omega \mathrm{CH}_{2}$ \\
\hline 4 & 28 & -1 & 30 & 1 & 28 & $6,4,2$ & $\left(v_{15}\right) v \mathrm{C}-\mathrm{C}+v \mathrm{C}-\mathrm{O}_{\mathrm{C}}$ \\
\hline
\end{tabular}

Figure 3 shows the stretching $v \mathrm{OH}, v \mathrm{C}=\mathrm{O}$ and in-plane-deformation $\delta \mathrm{OH}_{\mathrm{C}}$ regions of the infrared spectra of GA/ $\mathrm{N}_{2} / \mathrm{Ar}$ matrices deposited at three different temperatures and compared to the GA/Ar spectrum. In the $v \mathrm{OH}$ stretching region of the spectrum of GA co-deposited at $15 \mathrm{~K}$ with the $\mathrm{N}_{2} / \mathrm{Ar}$ $=1 / 4000$ mixture several new maxima due to the GA $\cdots \mathrm{N}_{2}$ complexes are distinguished. They are situated below the $\mathrm{vOH}$ of the SSC conformer at 3549.5, 3546.5 and 3542.0/3540.0 (a doublet) $\mathrm{cm}^{-1}$. Additionally, a broadening on the lower wavenumber side of the $\mathrm{vOH}$ of the SSC monomer was found at $3556 \mathrm{~cm}^{-1}$ (at $15 \mathrm{~K}$ seen as a weak shoulder and better shaped at 18 and $25 \mathrm{~K}$ ). The same set of bands (being much weaker) was observed in the $\mathrm{vOH}$ region when GA was deposited with an extremely diluted $\mathrm{N}_{2} / \mathrm{Ar}$ (in the case when small leak in the vacuum system was present). This indicates that all mentioned spectral features are due to the $1: 1 \mathrm{GA} \cdots \mathrm{N}_{2}$ species. 

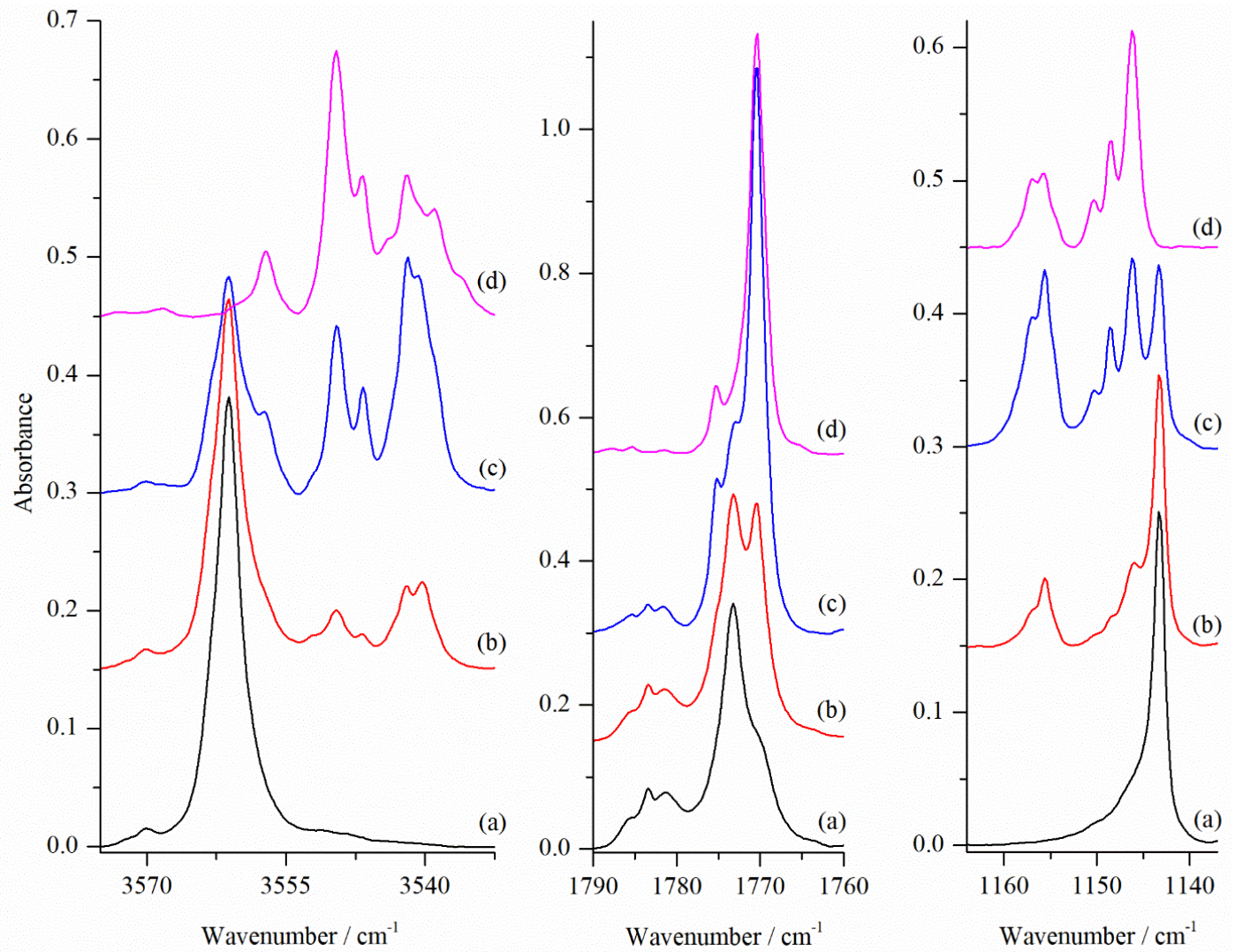

Figure 3. The $v \mathrm{OH}, \delta \mathrm{OH}_{\mathrm{C}}$ and $\nu \mathrm{C}=\mathrm{O}$ regions of the infrared spectra of GA co-deposited with $\mathrm{N}_{2} / \mathrm{Ar}=$ $1 / 4000$ at $15 \mathrm{~K}, 18 \mathrm{~K}$ and $25 \mathrm{~K}$ (measurement at $10 \mathrm{~K}$ ) (traces (b-d), respectively, compared with GA/Ar spectrum (a).

As shown in Figure 3, when matrices were deposited at $15 \mathrm{~K}$ and $18 \mathrm{~K}$ the most intense of all new bands present in the $\mathrm{vOH}_{\mathrm{C}}$ region was a doublet at $3542.0 / 3540.0 \mathrm{~cm}^{-1}$. Each of the bands observed in the $\mathrm{vOH}_{\mathrm{C}}$ region has its counterpart in the in-plane-bending $\delta \mathrm{OH}_{C}$ region. Here, in the region of $1140-1160 \mathrm{~cm}^{-1}$, where we find the SSC monomer band at $1143.5 \mathrm{~cm}^{-1}$, a new set of bands due to the GA $\cdots \mathrm{N}_{2}$ complex appeared at higher wavenumbers. A doublet in the $\mathrm{vOH}_{\mathrm{C}}$ region at $3542.0 / 3540.0 \mathrm{~cm}^{-1}$ and a weak band at $3557.0 \mathrm{~cm}^{-1}$ (shifted by $-19 /-21 \mathrm{~cm}^{-1}$ and $-4 \mathrm{~cm}^{-1}$ ) fit well to the calculated positions of the stretching vibrations of carboxylic and alcoholic groups, respectively, in the most stable SSC1 complex. The calculated $\Delta v \mathrm{OH}$ shifts in SSC1 form equal to -31 and $-5 \mathrm{~cm}^{-1}$ for the hydrogen bonded carboxylic hydroxyl group and for non-hydrogen bonded alcoholic $\mathrm{OH}$, respectively. Similar agreement was also found in other spectral regions as presented in Table 4. For the in-plane-deformation $\delta \mathrm{OH}_{\mathrm{C}}$ mode the most intense doublet in the spectra of matrices deposited at 15 and $18 \mathrm{~K}$ at $1157.0 / 1155.5 \mathrm{~cm}^{-1}$ is blue-shifted by 13.5 and $12 \mathrm{~cm}^{-1}$ relative to the corresponding monomer absorption. This is also in a very good agreement with the predicted shift of $15 \mathrm{~cm}^{-1}$.

Both in $\vee \mathrm{OH}_{\mathrm{C}}$ and $\delta \mathrm{OH}_{\mathrm{C}}$ regions additional bands are present, and they are slightly shifted compared with those already assigned above. There are several possible reasons for the observed additional absorptions in the spectra. One of them is that there exists different structures of SSC $\cdots \mathrm{N}_{2}$ complexes. As shown in Table 4 the $v \mathrm{OH}$ shifts predicted for SSC2 and SSC3 complexes do not fit to any of the observed bands. This indicates that there is only one type of complex in the experimental conditions used instead of three different SSC complexes identified computationally. Consequently, only the SSC1 structure is to be formed in the argon matrix, and another explanation should be found for the additional bands in the $\mathrm{vOH}_{\mathrm{C}}$ and $\delta \mathrm{OH}_{\mathrm{C}}$ regions. The most obvious explanation is the presence of multiple trapping sites in the matrix, which can slightly perturb the structures of the complexes. For the SSC1 structure, the position of the $\mathrm{N}_{2}$ molecule relative to the $\mathrm{OH}$ group of the carboxylic moiety 
is most susceptible to changes induced by the environment. Depending on the local structure of the surrounding argon atoms, the hydrogen-bonded $\mathrm{N}_{2}$ tail is either bent or elongated compared to the most favourable site structure.

This idea of perturbed complex structures giving different spectral features was tested with a relaxed potential energy scan for the bending motion of the $\mathrm{N}_{2}$ molecule in the hydrogen-bonded SSC1 complex. For each step the $\mathrm{C} 4 \mathrm{O} 6 \mathrm{~N} 10$ angle describing a position of $\mathrm{N}_{2}$ relative to the GA was fixed at values slightly different than that obtained for the global SSC1 minimum (the C4O6N10 angle equals to 104.1 degrees) and all remaining parameters were optimized. The range of angle changes was between 94.0 and 119.0 degrees with a step of 2.5 degrees. Figure 4 shows the changes of the $\mathrm{vOH}$ wavenumber calculated for each point of the relaxed potential energy scan. The relative electronic energy of the SSC1 complex and the corresponding changes of the $\nu \mathrm{C}=\mathrm{O}$ and $\delta \mathrm{OH}_{\mathrm{C}}$ wavenumbers are presented in Figure S1 (Supplementary Materials Information). All points presented in Figure 4 and Figure S1 represent structures that all have positive wavenumbers in their computed spectra. Accordingly, the bending movement of the $\mathrm{N}_{2}$ molecule in the studied range results in very small changes in energy indicating that the potential energy surface is relatively flat. The changes of the wavenumbers of the vibrations depend on how much the nitrogen molecule is averted from its equilibrium position. The highest deviations of the $v \mathrm{OH}_{\mathrm{C}}$ and $\delta \mathrm{OH}_{\mathrm{C}}$ wavenumbers are between 5 and $9 \mathrm{~cm}^{-1}$ whereas that obtained for $v \mathrm{C}=\mathrm{O}$ is smaller and equals ca. $2 \mathrm{~cm}^{-1}$. The predicted values of the $\Delta v \mathrm{OH}_{\mathrm{C}}$ and $\Delta \delta \mathrm{OH}_{\mathrm{C}}$ are of the same order as differences in positions of the components of the absorption in the experimental $\mathrm{OH}$ stretching and in-plane deformation regions. Therefore, it is plausible to assume that the additional features observed in the spectra are due to the SSC1 complex in different local structures (sites) in the matrix.

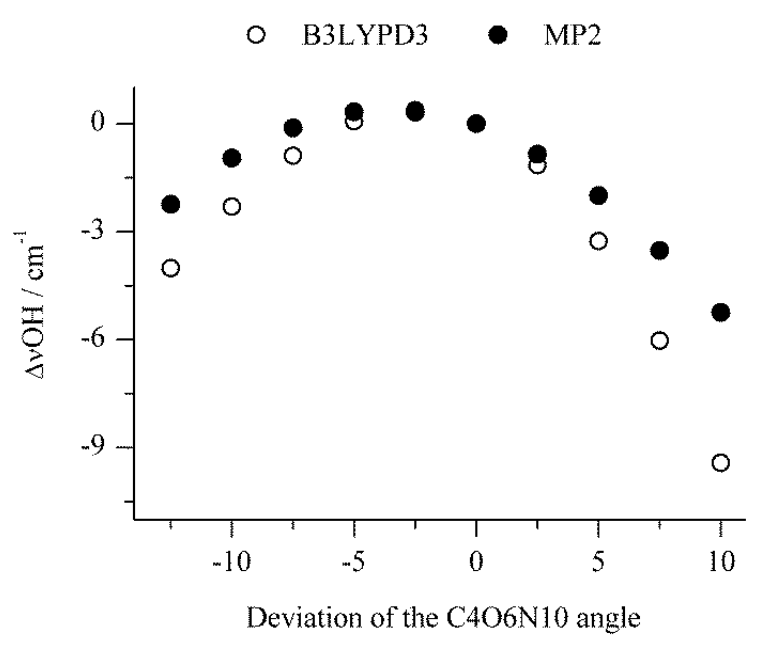

Figure 4. Plot showing changes of the $\mathrm{vOH}$ value calculated for each point of the relaxed potential energy scan for the bending movement of the $\mathrm{N}_{2}$ molecule in SSC1 complex calculated at the B3LYPD3 and MP2 levels with $6-311++G(2 d, 2 p)$ basis set versus deviation of the $C 406 \mathrm{~N} 10$ angle. The zero value of this angle corresponds to the global minimum value.

In the middle panel of Figure 3, an intense new feature appeared upon complex formation in the $v \mathrm{C}=\mathrm{O}$ region. The intense band at $1770.5 \mathrm{~cm}^{-1}$ is red shifted by $2.5 \mathrm{~cm}^{-1}$ compared to the $v C=\mathrm{O}$ of SSC monomer $\left(1773 \mathrm{~cm}^{-1}\right)$. Its position and intensity are consistent with those predicted computationally for the $v \mathrm{C}=\mathrm{O}$ in SSC1 structure (see Table 4). No site splitting in the $\Delta v \mathrm{C}=\mathrm{O}$ region was detected in agreement with the small wavenumber changes predicted for this mode upon $\mathrm{N}_{2}$ movement (see Figure S1). This is also in accordance with the explanation of site structures observed for the $\mathrm{OH}$ stretching vibrations, which are due to the movement of the nitrogen molecule in the hydrogen-bonded bridge. The $\mathrm{rC}=\mathrm{O}$ mode is insensitive to these changes. 
Figure 5 shows the influence of the matrix annealing in the $v \mathrm{OH}, v \mathrm{C}=\mathrm{O}$ and $\delta \mathrm{OH}_{\mathrm{C}}$ regions of the $\mathrm{GA} / \mathrm{N}_{2} / \mathrm{Ar}$ matrices deposited at $15 \mathrm{~K}$. The difference spectra shown in the upper part of the figure indicate that the components of the $v \mathrm{OH}$ absorption were differently affected by rising temperature to $33 \mathrm{~K}$. Combining the information from Figures 4 and 5 indicates that deposition of the matrix at different temperatures favour different local structures of the SSC1 complex. Annealing of the matrix influences the site structure very little. In the $\mathrm{OH}$ stretching region, there appear mainly two sites (corresponding to doublet at 3542 and $3540 \mathrm{~cm}^{-1}$, and a band at $3546.5 \mathrm{~cm}^{-1}$ ) which yield hydrogen-bonded complexes from close contact pairs between nitrogen and GA. The third site, evidenced by a band at $3549.5 \mathrm{~cm}^{-1}$, appears in deposition but it is not growing upon annealing.
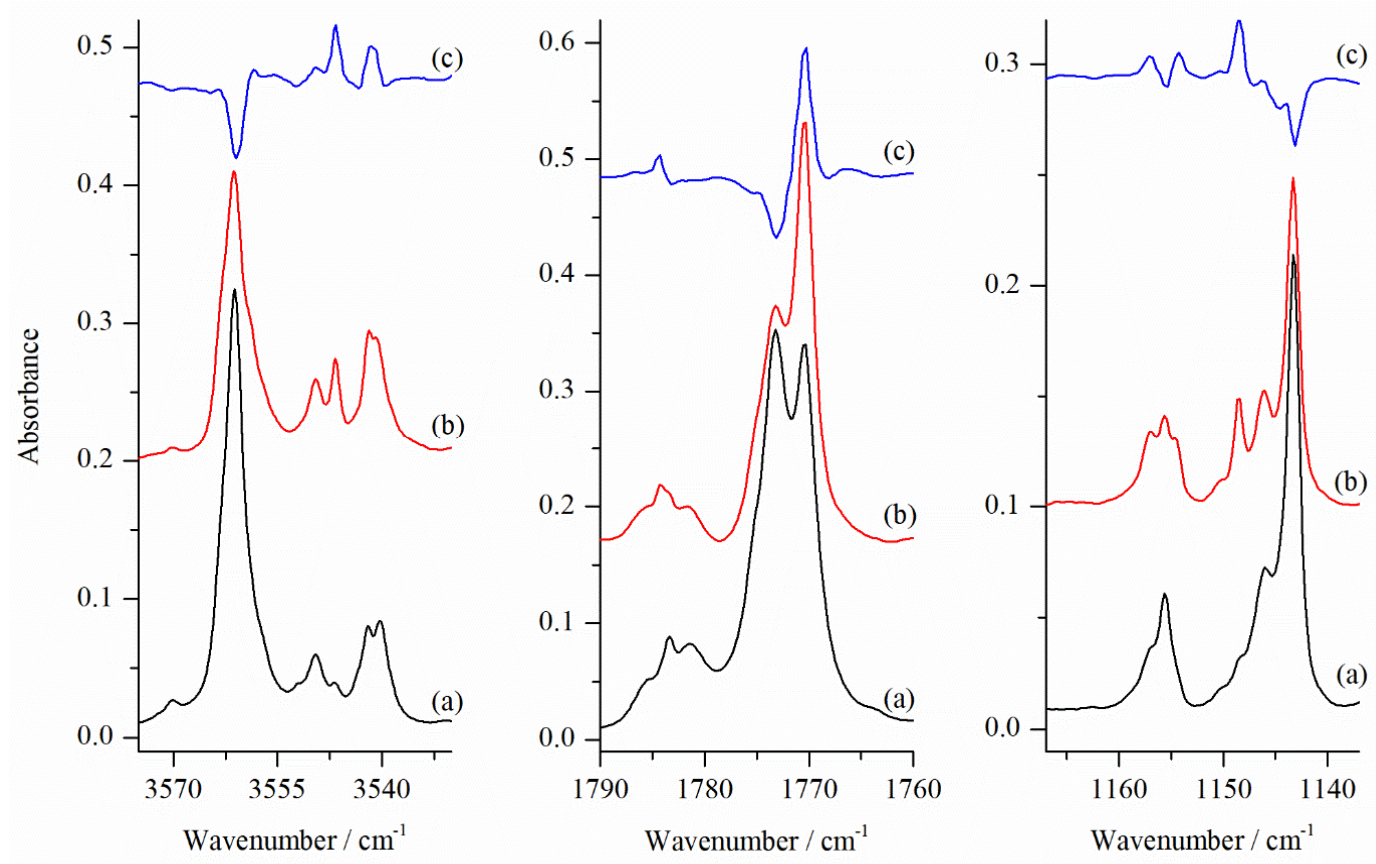

Figure 5. The $\gamma \mathrm{OH}, \delta \mathrm{OH}_{\mathrm{C}}$ and $\nu \mathrm{C}=\mathrm{O}$ regions of the infrared spectra of GA co-deposited with $\mathrm{N}_{2} / \mathrm{Ar}$ $=1 / 4000(\mathbf{a})$ at $15 \mathrm{~K}$ and $(\mathbf{b})$ after annealing at $33 \mathrm{~K}$ (measurement at $10 \mathrm{~K})$ and $(\mathbf{c})$ the corresponding difference spectrum (b) minus (a). The bands at 3561.0, 1773.0 and $1143.0 \mathrm{~cm}^{-1}$ belong to the SSC monomer.

\section{Conclusions}

Matrix isolation FTIR spectroscopy and computational chemistry have been employed to study glycolic acid complexes with a nitrogen molecule in an argon matrix. Computationally, at the MP2 level, 11 different GA $\cdots \mathrm{N}_{2}$ complex structures were obtained for the SSC, GAC and AAT glycolic acid monomers. For SSC and GAC the largest interactions between the complex subunits were found for structures, where the nitrogen molecule forms a linear hydrogen-bonded structure with the GA subunit. In the case of AAT a cyclic structure involving both $\mathrm{OH}$ groups appeared to be the most tightly bound instead of the linear hydrogen-bonded structure.

In the experimental conditions used, the glycolic acid molecule is prevalently complexed with one nitrogen molecule. Deposition of the matrix in different temperatures indicate that there are three different local site structures of the complex formed. Annealing experiments are helpful in distinguishing the different sites from each other, and here two of the three sites were found to be further enhanced from local near contact pairs. The existence of site structures of one complex is also implied by the computational methods based on the vibrational shifts computed for the complexes. Additionally, these sites are stable enough that they could not be interconverted upon annealing experiments.

In conjunction with recent Raman spectroscopy study [22] and the results obtained here by FTIR and computational methods, it can be concluded that co-depositing GA and $\mathrm{N}_{2}$ in a large excess 
argon matrix produces only hydrogen bonded SSC $\cdots \mathrm{N}_{2}$ complexes occupying three different local matrix sites. In order to gain insight on the local structures and their interconversion dynamics upon annealing molecular dynamics simulations of the doped matrices and irradiation experiments should be performed. The latter approach is employed in the following paper [46], where the site-selective chemistry of SSC $\cdots \mathrm{N}_{2}$ is be used to unravel some structural features of the sites and their impact on the photo-induced processes.

Supplementary Materials: The following are available online, Figure S1. Plot showing changes of the energy, $\nu \mathrm{C}=\mathrm{O}, \delta \mathrm{OH}$ wavenumbers calculated for each point of the relaxed potential energy scan for the bending movement of the $N_{2}$ molecule in SSC1 complex calculated at the B3LYPD3 and MP2 levels with 6-311++G(2d,2p) basis set versus deviation of the C4O6N10 angle. Table S1. Cartesian coordinates of $\mathrm{N}_{2}$, GA monomers and GA $\cdots \mathrm{N}_{2}$ complexes of the 1:1 stoichiometry calculated at MP2/6-311++G(2d,2p) level.

Author Contributions: Conceptualization: M.W. and J.L.; methodology: M.W., J.L. and J.M.E.A.; formal analysis: J.K., I.K., M.W.; investigation: I.K., J.K., J.M.E.A.; resources: M.W. and J.L.; data curation: M.W., J.M.E.A. and J.L.; writing—original draft preparation: M.W. and J.L.; writing—review and editing: M.W., J.L. and J.M.E.A.; visualization: I.K. and J.K.; supervision: M.W. and J.L.; project administration: M.W. and J.L.; funding acquisition: M.W. and J.L.

Funding: This research was funded by the National Science Centre project no. 2013/11/B/ST4/00500 (at UWr to M.W.) and Academy of Finland project no. 286844 (at JYU to J.L.).

Acknowledgments: Allocation of computer time from the Wrocław Centre for Networking and Supercomputing (Wroclaw, Poland) is gratefully acknowledged.

Conflicts of Interest: The authors declare no conflict of interest.

\section{References}

1. Pimentel, G.C.; McClellan, A.L. Hydrogen Bond; Freeman: San Francisco, CA, USA, 1960.

2. Scheiner, S. Hydrogen Bonding. A Theoretical Perspective; Oxford University Press: New York, NY, USA, 1997.

3. Klemperer, W.; Vaida, V. Molecular complexes in close and far away. Proc. Natl. Acad. Sci. USA 2006, 103, 10584-10588. [CrossRef] [PubMed]

4. Vigasin, A.A.; Slanina, Z. (Eds.) Molecular Complexes in Earth's, Planetary, Cometary, and Interstellar Atmospheres; World Scientific Publishing Co. Pte. Ltd.: Singapore, 1998.

5. Vaida, V. Perspective: Water cluster mediated atmospheric chemistry. J. Chem. Phys. 2011, 135, 020901. [CrossRef] [PubMed]

6. Khriachtchev, L. Matrix isolation studies of noncovalent interactions: More sophisticated approaches. J. Phys. Chem. A 2015, 119, 2735-2746. [CrossRef] [PubMed]

7. Khriachtchev, L. Physics and Chemistry at Low Temperatures; Pan Stanford Publishing: Singapore, 2012.

8. Wierzejewska, M.; Olbert-Majkut, A. Matrix isolation spectra and ab initio calculations of isothiocyanic acid complexes with carbon monoxide. J. Phys. Chem. A 2003, 107, 1928-1934. [CrossRef]

9. Olbert-Majkut, A.; Lundell, J.; Wierzejewska, M. Light-induced opening and closing of the intramolecular hydrogen bond in glyoxylic acid. J. Phys. Chem. A 2014, 118, 350-357. [CrossRef] [PubMed]

10. Lundell, J.; Olbert-Majkut, A. Isolated glyoxylic acid-water complexes in low temperature argon matrices. Spectrochim. Acta A. 2015, 136, 113-121. [CrossRef] [PubMed]

11. Haupa, K.; Bil, A.; Mielke, Z. Donor-acceptor complexes between ammonia and sulfur trioxide: An FTIR and computational study. J. Phys. Chem. A 2015, 119, 10724-10734. [CrossRef] [PubMed]

12. Haupa, K.; Bil, A.; Barnes, A.; Mielke, Z. Isomers of the acetic acid-water complex trapped in an argon matrix. J. Phys. Chem. A 2014, 119, 2522-2531. [CrossRef]

13. Krupa, J.; Wierzejewska, M. Structural and spectroscopic properties of complexes formed between HNCS and $\mathrm{SO}_{2}$ in low temperature matrices. Spectrochim. Acta A. 2017, 183, 144-149. [CrossRef]

14. Biczysko, M.; Krupa, J.; Wierzejewska, M. Theoretical studies of atmospheric molecular complexes interacting with NIR to UV light. Faraday Discuss. 2018, 212, 421-441. [CrossRef]

15. Hollenstein, H.; Schär, R.W.; Schwizgebel, N.; Grassi, G.; Günthard, H.H. A transferable valence force field for polyatomic molecules. A scheme for glycolic acid and methyl glycolate. Spectrochim. Acta A 1983, 39, 193-213. [CrossRef] 
16. Hollenstein, H.; Ha, T.K.; Günthard, H.H. IR induced conversion of rotamers, matrix spectra, ab initio calculation of conformers, assignment and valence force field of trans glycolic acid. J. Mol. Struct. 1986, 146, 289-307. [CrossRef]

17. Reva, I.D.; Jarmelo, S.; Lapinski, L.; Fausto, R. IR-induced photoisomerization of glycolic acid isolated in low-temperature inert matrices. J. Phys. Chem. A 2004, 108, 6982-6989. [CrossRef]

18. Reva, I.D.; Jarmelo, S.; Lapinski, L.; Fausto, R. First experimental evidence of the third conformer of glycolic acid: Combined matrix isolation, FTIR and theoretical study. Chem. Phys. Lett. 2004, 389, 68-74. [CrossRef]

19. Halasa, A.; Lapinski, L.; Reva, I.; Rostkowska, H.; Fausto, R.; Nowak, M.J. Near-infrared laser-induced generation of three rare conformers of glycolic acid. J. Phys. Chem. A 2014, 118, 5626-5635. [CrossRef]

20. Ahokas, J.M.E.; Kosendiak, I.; Krupa, J.; Wierzejewska, M.; Lundell, J. High vibrational overtone excitation-induced conformational isomerization of glycolic acid in solid argon matrix. J. Raman Spectrosc. 2018, 49, 2036-2045. [CrossRef]

21. Ahokas, J.; Kosendiak, I.; Krupa, J.; Lundell, J.; Wierzejewska, M. FTIR matrix isolation and theoretical studies of glycolic acid dimers. J. Mol. Struct. 2018, 1163, 294-299. [CrossRef]

22. Ahokas, J.M.E.; Kosendiak, I.; Krupa, J.; Lundell, J.; Wierzejewska, M. Raman spectroscopy of glycolic acid complexes with $\mathrm{N}_{2}$. J. Mol. Struct. 2019, 1183, 367-372. [CrossRef]

23. Frisch, M.J.; Trucks, G.W.; Schlegel, H.B.G.; Scuseria, E.; Robb, M.A.; Cheeseman, J.R.; Scalmani, G.; Barone, V.; Petersson, G.A.; Nakatsuji, H.; et al. Gaussian 16, Revision A.03; Gaussian Inc.: Wallingford, CT, USA, 2016.

24. Head-Gordon, M.; Pople, J.A.; Frisch, M.J. MP2 energy evaluation by direct methods. Chem. Phys. Lett. 1988, 153, 503-506. [CrossRef]

25. Head-Gordon, M.; Head-Gordon, T. Analytic MP2 frequencies without fifth order storage: Theory and application to bifurcated hydrogen bonds in the water hexamer. Chem. Phys. Lett. 1994, 220, 122-128. [CrossRef]

26. Frisch, M.J.; Head-Gordon, M.; Pople, J.A. Semi-direct algorithms for the MP2 energy and gradient. Chem. Phys. Lett. 1990, 166, 281-289. [CrossRef]

27. Sæbø, S.; Almlöf, J. Avoiding the integral storage bottleneck in LCAO calculations of electron correlation. Chem. Phys. Lett. 1989, 154, 83-89. [CrossRef]

28. Becke, A.D. Density-functional exchange-energy approximation with correct asymptotic behaviour. Phys. Rev. A 1988, 38, 3098-3100. [CrossRef] [PubMed]

29. Lee, C.; Yang, W.; Parr, R.G. Development of the Colle-Salvetti correlation-energy formula into a functional of the electron-density. Phys. Rev. B 1988, 37, 785-789. [CrossRef] [PubMed]

30. Becke, A.D. Density-functional thermochemistry. III. The role of exact exchange. J. Chem. Phys. 1993, 98, 5648-5652. [CrossRef]

31. Miehlich, B.; Savin, A.; Stoll, H.; Preuss, H. Results obtained with the correlation-energy density functionals of Becke and Lee, Yang and Parr. Chem. Phys. Lett. 1989, 157, 200-206. [CrossRef]

32. Grimme, S.; Antony, J.; Ehrlich, S.; Krieg, H. A consistent and accurate ab initio parameterization of density functional dispersion correction (DFT-D) for the 94 elements H-Pu. J. Chem. Phys. 2010, 132, 154104. [CrossRef]

33. Boys, S.F.; Bernardi, F. Calculation of small molecular interactions by differences of separate total energies-Some procedures with reduced errors. Mol. Phys. 1970, 19, 553-566. [CrossRef]

34. Simon, S.; Duran, M.; Dannenberg, J.J. How does basis set superposition error change the potential surfaces for hydrogen bonded dimers? J. Chem. Phys. 1996, 105, 11024-11031. [CrossRef]

35. Bader, R.F.W. Atoms in Molecules. A Quantum Theory; Oxford University Press: Oxford, UK, 1990.

36. Keith, T.A. AIMAll (Version 12.09.23); TK Gristmill Software: Overland Park, KS, USA, 2012; Available online: aim.tkgristmill.com.

37. Bader, R.F.W.; Essen, H. The characterization of atomic interactions. J. Chem. Phys. 1984, 80, 1943. [CrossRef]

38. Grabowski, S.J. What is the covalency of hydrogen bonding? Chem. Rev. 2011, 111, 2597-2625. [CrossRef] [PubMed]

39. Kumar, P.S.V.; Raghavendra, V.; Subramanian, V. Bader's Theory of Atoms in Molecules (AIM) and its applications to chemical bonding. J. Chem. Sci. 2016, 128, 1527-1536. [CrossRef]

40. Cerpa, E.; Krapp, A.; Vela, A.; Merino, G. The implications of symmetry of the external potential on bond paths. Chem. Eur. J. 2008, 14, 10232-10234. [CrossRef] [PubMed] 
41. Lane, J.R.; Contreras-Garcia, J.; Piquemal, J.-P.; Miller, B.J.; Kjaergaard, H.G. Are bond critical points really critical for hydrogen bonding? J. Chem. Theor. Comput. 2013, 9, 3263-3266. [CrossRef] [PubMed]

42. Lundell, J.; Räsänen, M.; Latajka, Z. Matrix isolation FTIR and ab initio study of complexes between formic acid and nitrogen. Chem. Phys. 1994, 189, 245-260. [CrossRef]

43. Wierzejewska-Hnat, M.; Latajka, Z.; Mielke, Z.; Ratajczak, H. Theoretical and infrared matrix isolation studies of the $\mathrm{CF}_{3} \mathrm{COOH}-\mathrm{N}_{2}$ system. J. Mol. Struct. 1985, 129, 229-235. [CrossRef]

44. Michalska, D.; Wysokiński, R. The prediction of Raman spectra of platinum(II) anticancer drugs by density functional theory. Chem. Phys. Lett. 2005, 403, 211-217. [CrossRef]

45. Wysokiński, R.; Michalska, D.; Bieńko, D.C.; Ilakiamani, S.; Sundaraganesan, N.; Ramalingam, K. Density functional study on the molecular structure, infrared and Raman spectra, and vibrational assignment for 4-thiocarbamoylpyridine. J. Mol. Struct. 2006, 791, 70-76. [CrossRef]

46. Kosendiak, I.; Ahokas, J.M.E.; Krupa, J.; Lundell, J.; Wierzejewska, M. Complexes of glycolic acid with nitrogen isolated in argon matrices. II. Vibrational overtone excitations. Molecules 2019, 24, 3245. [CrossRef]

Sample Availability: Not available.

(C) 2019 by the authors. Licensee MDPI, Basel, Switzerland. This article is an open access article distributed under the terms and conditions of the Creative Commons Attribution (CC BY) license (http://creativecommons.org/licenses/by/4.0/). 